\title{
A Comparative Study of the Current Status of Original Songs in Colleges and Universities
}

\author{
Qunli Yan \\ Xi'an Translate University, Xi'an 710105, China \\ madonna7878@qq.com
}

Keywords: colleges and universities; original song; present situation

\begin{abstract}
As an important gathering place for popular music audience, there are more and more students in colleges and universities who like original music, but the quality of original music works in colleges and universities is not high, and the production is not professional, so it is difficult to be accepted by the market. In view of these problems, taking the Xi'an Fanyi University as an example, this paper makes an analysis of various circumstances of original songs in colleges and universities, and draws a conclusion that colleges and universities are short of related knowledge, equipment, professional training, management and production of funds. In theory, to strengthen the awareness of the popularization of original songs in colleges and universities plays an active role in the propaganda and cultural construction of colleges and universities; for the creator, they have the opportunity and stage to display and develop their talents.
\end{abstract}

\section{The Development of Pop Music Put Forward New Requirements for Original Songwriters in Colleges and Universities.}

Pop music has developed for more than a century since its birth in the late nineteenth Century and early twentieth Century in the United States. It has experienced the interaction and integration of various styles, genres, regions and other factors, and has developed into a cultural form affecting human life. In the early years of the last century, the embryonic form of popular music was only the medium of celebrating life, confiding suffering and expressing the demands of the working class for more than a century as the spare time of the working people. Nowadays, pop music has developed into an art form with different styles and regional cultural features, and has merged different types of art. Rhythm, scale, style, national music and classical music become the most diverse and systematic forms of music. At the same time, it has become one of the most influential technological and cultural industries in the whole human society. In today's human life, pop music has been an integral part of everyone's life. The digital music, which has emerged from the late last century's black gum records, tapes, CD (DVD) CDs to the turn of the century, leads the development of science and technology in its own development and changes through different media shadows. People's lives have become a cultural tool for people to express their feelings, entertain their lives, and have strong exchanges and economic development. According to the research report published by the China industry information network in February 2016, the global music industry has reached \$14 billion 970 million in the music industry chain that coexisted with black rubber records, CD (DVD) CDs, digital downloads and streaming media in 2014. Thus, it can be seen that music can not be replaced in the development of human society and culture.

With the development of the music industry, the market and audience also put forward more requirements for Chinese pop music producers.

\section{The Present Situation of Original Songs in Xi'an University}

In April 2017, the author and the research team carried out a survey on the original music creation of the universities in Xi'an, including four Xi'an universities including the Xi'an FanYi University, 
including three other Xijing University, Xi'an Peihua University and Xi'an Institute of Finance and Economics. Through close communication with the students and 380 investigations The random distribution of the volume, we generally understand that four college students have a high degree of awareness and attention to popular music. Among the four types of music, such as pop music, classical music, folk music, jazz and other types of music, $42.5 \%$ of the students like pop music. More than $16 \%, 76 \%$ of the students chose "don't know"; in their eyes, the school's original music development is still in the initial stage, the school also lacks the platform to show the author and work of the original song. 34\% of the students think the limitation of the environment and equipment is the primary reason, and another $42 \%$ of the students recognize that the lack of professional knowledge of the college students is their creation. In addition, $81 \%$ of the students hope to hear their own original songs in their own school, so it can be seen that college students have higher expectations of their own original music.

\section{SWOT Analysis of Original Song Creation in Xi'an Colleges and Universities -- Taking Xi'an Fanyi University as an Example}

Since my participation in the Xi'an Fanyi University in 2007, I have created more than 50 songs with different styles and different styles, which are well received by the school and outside the school, including "happy birthday, my western translation" for the 20th anniversary school celebration party of Xi'an Fanyi University and the singing style song "beautiful" for the school students. The western translation, my home, the theme songs for Xi'an Fanyi University in 2015, 2016 and the new year's Day party in 2017, "dream in the road", "run", "WE ARE FAMILY" and so on. Based on the creative experience of more than 20 years of original songs, this paper takes Xi'an Fanyi University as an example to make an SWOT analysis of the creation of original songs in Colleges and universities in Xi'an.

\subsection{Advantage (S)}

Since the founding of the Xi'an Fanyi University has been a leader in the private university, in more than 60 societies, the music related organizations are not in a small number, and the number of students who love music is even bigger. Among these students, many students who like to write songs gather together to learn from each other. After years of development, the scale of the original music creation is gradually large and the related cultural inheritance is gradually formed. Many of the original music creators, band musicians, and musicians have gone through four years' study and life of the University. After going to school, he worked in the north and Guangzhou and other large cities. The teachers of the school have played a very positive role in the original songs of our school. The students who like the original songs have the professional teachers to guide the creation, and have the corresponding rehearsal ground and equipment for the students to study and rehearse, and the related venues let the students have the stage to show their talents and works.

\subsection{Inferiority (W)}

Although in many colleges and universities, our school has a great strength in the second class and the community, but there are many public colleges and universities, there is still a certain gap, mainly in the rehearsal site, the old and the lack of equipment, students need to update more and larger sites as active sites; furthermore, our school correspondingly The proportion of professional instructors is seriously inadequate and the number of teachers who can guide students to create songs is less. Increasing this input will certainly enhance the students' creative level and the competitiveness of their works. Secondly, our school is far away from the city of Xi'an, and compares other colleges and universities near the city, and our students participate in social practice, competition and Other social activities are very difficult. Schools should hold more related activities in the school, invite some original musicians with certain fame or influence in the society as instructors or visiting professors to provide corresponding tutors for our school students who love original music, and increase public vehicles for our school. The activity of the students to provide convenience. 


\subsection{Opportunity $(0)$}

Xi'an as the capital of thirteen dynasties, China new starting point of the Silk Road, in the city center in a number of new countries, "The Belt and Road" and "Xi'an-Xianyang integration" and the construction of Chinese third international metropolis under the background of economic development and the city's rising and change rapidly, so the rapid development in the state. West The "soft power" of an urban "soft power" began to be more linked to the cultural construction of the city, and more relevant cultural and artistic talents were needed to work and live in Xi'an to build a "big Xi'an" in our ideal. In March 2017, the government of Xi'an made a major adjustment to the settlement policy of Xi'an. In one year, more and more policies were relaxed, and more and more people settled in Xi'an because of their good policy. The author himself was the first beneficiary of the new policy. Although most of the talents related to the music industry are concentrated in the front-line cities such as North and Guangzhou, the development speed and prospects of Xi'an, with the scientific urban planning and good development policy, more opportunities will be left to the people who dream of music. As a cradle of original music dream, our school is bound to contribute more talents to Xi'an for the society.

\subsection{Threat (T)}

Speaking of the greatest threat of original music, I think it is the habit of living and the impetuous atmosphere of society today. Now more and more people rely on mobile phones and networks, and fewer and fewer people are willing to read. According to the media reports, the average volume of Chinese reading is only 0.7, less than 7 in Japan and 40 in Korea. 55 in Russia, and among the people who rely on mobile phones and networks, college students are a huge group. Many college students are rarely involved in other extracurricular books except textbooks. This is a devastating blow to the accumulation and study of original songs, and more and more variety competitions and reality shows on TV and the Internet are on the Internet. A lot of students who want to be famous for a night have more ideas and time, and many students would prefer to take leave and take part in these competitions and TV or network programs. In this kind of impetuous atmosphere, there are fewer people willing to be quiet and creative. In addition, the depression of Chinese record industry also leads to many singers. It is also one of the threats to the creation of Chinese popular music.

\section{Implementation Plan of Original Music Clubs in Colleges and Universities -- Taking Xi'an Fanyi University as an Example}

First, through the school broadcasting station, the school FM station, the Baidu post bar, the school official micro-blog, the school official WeChat public number and other media in the school scope, vigorously publicized the original music service, and then began to build the "Xi'an FanYi University original music society" through the influence of the League Committee in the school. It is possible for the Federation of students' associations to catch up with the establishment, and to post the posters in the main road of the school and to set up the exhibition platform to leave the students interested in the music. The number of people who are interested in music can reach more than 10 people for a period of 3 months, and the group of interest groups can develop their own members at the same time. To build a group of cadres, democratically elected a president and a deputy chief of the community, the Minister of the Department of foreign affairs, the Minister of the study department, the Minister of the Department of the organization, the Minister of the Ministry of propaganda and the Minister of propaganda, and the four ministers in charge of their own members.

Secondly, after the 3 months of interest groups reached the standard, they applied to the School Committee for an office room, used to hold various internal meetings and small internal activities, and set up the management system for the community and the office of the community. After the meeting, we learned the relevant documents and submitted the application to the League Committee. The application for interest groups was formally transferred to the League Committee of our school. An official organization for management. 
Third, after the formal establishment of the community, in September each year with other school associations, the school league committee under the organization of the new, and two times a year to the school committee to hold the theme activities and related activities funds, around the creation of original songs, to carry out a variety of different scale and content of the study, exhibition and performance activities, for the excellent The original works of MV, or the big movie online, add a strong touch to the business card of Xi'an FanYi University.

Fourth, together with our school of innovation and entrepreneurship, we jointly set up a recording studio for the rehearsal and recording of students' works, and serve as the training base for the school original music society.

\section{Problems in the Creation of Original Music Clubs in Colleges and Universities}

\subsection{It must be nonprofit to start a community}

After the enrollment of new students in September each year, the school committee organizes each student organization to carry out new students' new activities. The new members are required to pay 10 yuan or 15 yuan per person to the club. The membership fee can not be used for the community or individual profit. It can only be used as a necessary fund for the organization of the club emblem and the purchase of office goods. After collecting the membership fee, the school committee will unify the receipt for the members and assist in the management of some of the surplus funds after the purchase of the above goods. When the community needs to use the surplus funds, the association should submit the relevant application to the school committee. Therefore, the collection of the membership fee and the non-profit of the society, the leaders of the association and other cadres are obliged to explain to the freshmen.

\subsection{The participants in the community and community activities}

The members of the association must be the students or teachers of the school. The participants of the community activities may be the teachers and students of the school, or the outside students who have agreed to participate in the activities by the school (including the teachers and students and leaders of the brothers college, the sponsor of the activities, the other instructors or the visiting professors), and the head of the community is obliged to be in the community. The meeting or activity scene introduces the relevant circumstances or the foreign guests attending the event.

\subsection{Evaluation of the effect of community activities}

After each application and completion of the club's theme activities, the head of the community should submit to the school league committee the invoices of the activities related to the activities summary and purchase of the activities. In the summary, there are a real number of participants, the scope, the participants' research on the activity satisfaction and the photo of the present field. The evaluation of the activities is the most important. It is an important indicator of the annual assessment of the stars. The leaders of the community should organize other Association cadres, issue questionnaires, and record the real and effective evaluation of community activities.

To sum up, the creation of original campus songs in Xi'an is only the initial stage of the germination, to protect the bud, we have a lot of work to do, it is a good choice to start the community. I hope in the future work life, we can hear more excellent original music works from universities, and see more college students' performance.

\section{References}

[1] Xu Yuanyong. On the current situation and development trend of Chinese pop music. Journal of Zhejiang Normal University (SOCIAL SCIENCE). Vol. (2015) No. 06, p. 231.

[2] Wang Siqi. The concept of "pop music" and its cultural characteristics. Music art (Journal of Shanghai Conservatory of Music). Vol. (2003) No. 03, p. 36. 